\title{
Integrating Divergent Epistemologies of the Two Influential Views on Organizational Knowledge Creation
}

Hammad Akbar, Management School, University of Liverpool, UK

\begin{abstract}
This paper integrates the divergent epistemologies of the organizational learning view and the knowledge-creation view on how new knowledge is created in organizations. The former view adopts an information-processing perspective and emphasizes the importance of deep knowledge and higherlevel learning, whereas the latter view adopts a social constructionist perspective and stresses the importance of tacit knowledge and interactive dialogue. The paper's integration uses the theorization of knowledge levels, specifically the shifts and movements in knowledge trajectories and the inverse relationship between the degree of tacitness and explicitness. The paper contributes greater coherence in our understanding of knowledge creation and generates new meaning/insights. The paper concludes by highlighting potential interpretations/insights and implications before presenting limitations and future research directions.
\end{abstract}

\section{KEYWORDS}

Knowledge Levels, Organizational Knowledge Creation, Organizational Learning, Tacit and Explicit Knowledge

\section{INTRODUCTION}

Organizational knowledge creation is the process of translating knowledge created by individual(s) into useful organizational knowledge (Nonaka \& von Krogh, 2006, 2009). Organizational knowledge creation is important because in the present-day knowledge-era where the widespread availability of information is taking competition to a new level, new knowledge is fast becoming the cornerstone of future success of organizations (Campanella, Derhy, \& Gangi, 2019; Mehralian, Nazari, \& Ghasemzadeh, 2018). Given this, it is imperative that we coherently understand organizational knowledge creation (Brix, 2017; Gärtner, 2013), without foregoing the freedom for varied interpretations and perspectives.

Organizational knowledge creation has been most influenced by two views - the organizational learning view and the knowledge-creation view. These views have divergent epistemological positions on how new knowledge is created in organizations. Epistemology is the way knowledge is obtained or the way we understand the world, and is often contrasted with ontology, or the study of being, or the way things exist (Scotland, 2012). The organizational learning view traces knowledge creation in deep knowledge and higher-level learning and is popularly reflected in double-loop learning models (Argyris, 1977; Argyris \& Schön, 1978, 1999). Learning is the process of gaining experience and developing cognitive and behavioural skills (DiBella, Nevis, \& Gould, 1996; Leroy \& Ramanantsoa, 1997). The knowledge-creation view, in contrast, emphasizes the importance of tacit knowledge and 
interactive dialogue (Nonaka, 1991, 1994; Nonaka \& Takeuchi, 1995). The two views offer divergent epistemologies; the organizational learning view is underpinned by the information-processing perspective (based on the individual-ontology), whereas the knowledge-creation view is underpinned by the social constructionist perspective (based on the collective ontology). However, in spite of the need for a coherent understanding of organizational knowledge creation, the epistemological positions of these two influential views remain to be integrated. This paper attempts to do just that.

This paper's integrative attempt uses the theorization of knowledge levels advanced earlier in the literature (Akbar, 2003; also Akbar, Baruch, \& Tzokas, 2008). Specifically, the paper uses the distinction between shifts and movements in knowledge to integrate learning and creativity, and the different degrees of tacitness of knowledge levels to integrate tacit and deep knowledge. The paper then uses the inverse relationship between the degrees of tacitness and explicitness to highlight the role of deviance in transferring/acquiring knowledge levels. The paper mainly focuses on the knowledge creation's epistemological dimension and a detailed discussion on the knowledge creation's ontological dimension is beyond its scope.

The paper's contribution is to bring greater coherence in our understanding of organizational knowledge creation and to open up freedom for variety of interpretations and new meaning/insights in the rather complex area of knowledge creation. The subsequent discussion first outlines the two views by highlighting their perspectives, focus, prescribed processes and creative outcomes. The next section identifies their underlying commonalities and key differences, including their relevant critique. The paper then integrates the two views based on the theorization of knowledge levels and their transformation advanced earlier in the literature. The paper concludes by articulating its contribution, implications, limitations and future research directions.

\section{DEFINITIONS AND CONCEPTS}

Knowledge is a difficult concept to define (Gourlay, 2006) because its manifestations are varied (Alvesson \& Karreman, 2001). Following Alavi \& Leidner (2001, p. 109) knowledge in this paper is defined as a justified belief that increases an entity's capacity for effective action. To account for the differences in levels of knowledge, this paper follows Akbar (2003) who defines knowledge as 'levels of objective truth' (or product) and their 'subjective and relative exploration' (or process). The Oxford Dictionary (2020) defines 'level', among others, as rank in scale or size of importance in a particular situation at a particular time. Subjective means depending upon on the person's perspective, i.e. the way of thinking, and objective means existing independently of our perceptions. Akbar (2003) argues that lower levels of knowledge are more explicit and thus easy to be transferred/ acquired, whereas higher levels of knowledge are less explicit and thus acquired through subjective and relative exploration, such as from the comparison of the intransitive and transitive dimensions of truth (Bhaskar, 1986) - more later.

Organizational knowledge creation is the process of making available and amplifying knowledge created by individuals as well as crystallizing and connecting it to an organization's knowledge system (Nonaka \& von Krogh, 2009). Organizational knowledge system is the collective representation of employees' skills, expertise and capabilities, existing products, services and systems, documents, repositories, routines, processes, practices and norms of an organization (Kane, 2017). Moreover, while new knowledge is often regarded as the replication and exploitation of existing knowledge (Cyert \& March, 1992), this paper approaches it in terms of new products, services and systems because they are intertwined with organizational competitiveness (Vezzoli et al., 2017).

Having highlighted the key definitions used, the paper now turns to the divergent epistemologies of the two influential views on organizational knowledge creation. 


\section{Influential Views on Organizational Knowledge Creation}

Organizational knowledge creation has been approached from varied perspectives; yet, scholars suggest that two views have been influential on the subject (e.g. Easterby-Smith, Antonacopoulou, Simm, \& Lyles, 2004; Stoyanov, 2018) - the organizational learning view (Argyris, 1977, 1991; Argyris \& Schön, 1978) and the knowledge-creation view (Nonaka, 1991, 1994; Nonaka \& Takeuchi, 1995). The subsequent discussion highlights their underlying perspectives, focus, prescribed processes and creative outcomes, as summarized in Table 1.

Table 1. The two influential views on organizational knowledge creation

\begin{tabular}{|c|c|c|}
\hline Key Features & The Organizational Learning View & The Knowledge-creation View \\
\hline Main Proponents & $\begin{array}{l}\text { Argyris, 1977, 1991, 1999; Argyris \& Schön, } \\
\text { 1978, 1980; Senge, } 1990\end{array}$ & $\begin{array}{l}\text { Nonaka, 1991, 1994; Nonaka \& Takeuchi, } \\
\text { 1995; see also Nonaka et al., 2001, 2008; Lam, } \\
\text { 2000; Von Krogh, Ichijo, \& Nonaka (2000) }\end{array}$ \\
\hline Origin & Cognitive Psychology & Michael Polanyi's work on tacit knowing \\
\hline $\begin{array}{l}\text { Ontological } \\
\text { Position }\end{array}$ & $\begin{array}{l}\text { Individual level ontology, which is applied at } \\
\text { the organizational level without modification }\end{array}$ & $\begin{array}{l}\text { Social constructionist ontology where reality is } \\
\text { not detached from the interpretative practices } \\
\text { of societal members }\end{array}$ \\
\hline Required Behaviors & $\begin{array}{l}\text { Active as opposed to passive learning } \\
\text { (organizations modifying the way they function } \\
\text { and enacting change in the environment) }\end{array}$ & $\begin{array}{l}\text { Knowledge creating behaviors } \\
\text { or 'a way of behaving' } \\
\text { (involving sharing/distributing knowledge, } \\
\text { immersion, reflection, etc.) }\end{array}$ \\
\hline $\begin{array}{l}\text { Underlying } \\
\text { Epistemological } \\
\text { Perspective }\end{array}$ & $\begin{array}{l}\text { Efficient information processing (for example, } \\
\text { information encoding, storage, retrieval and } \\
\text { use). }\end{array}$ & $\begin{array}{l}\text { Knowledge sharing and distribution (as tacit } \\
\text { knowledge is transferred/acquired through } \\
\text { activities, such as observation-imitation- } \\
\text { practice, joint problem-solving, experience } \\
\text { sharing, etc.) }\end{array}$ \\
\hline $\begin{array}{l}\text { Epistemological } \\
\text { Focus }\end{array}$ & $\begin{array}{l}\text { Deep knowledge (or know-why) rather than } \\
\text { superficial knowledge }\end{array}$ & $\begin{array}{l}\text { Tacit knowledge which is interchangeable with } \\
\text { explicit knowledge }\end{array}$ \\
\hline $\begin{array}{l}\text { Prescribed } \\
\text { Processes }\end{array}$ & Higher-level as opposed to lower-level learning & $\begin{array}{l}\text { Social interactions and tacit-explicit knowledge } \\
\text { conversion ((for example,) }\end{array}$ \\
\hline $\begin{array}{l}\text { Special Feature } \\
\text { of Prescribed } \\
\text { Processes }\end{array}$ & $\begin{array}{l}\text { Challenging and questioning of the underlying } \\
\text { assumptions (double-loop learning) }\end{array}$ & $\begin{array}{l}\text { Reflective Dialogue (to synthesize the conflict } \\
\text { between creativity and efficiency) }\end{array}$ \\
\hline Outcome & $\begin{array}{l}\text { Knowledge creation is one of the learning } \\
\text { outcomes, and reflects in improvement in } \\
\text { existing knowledge as well as a modification } \\
\text { of the way an organization behaves (theory-of- } \\
\text { action) }\end{array}$ & $\begin{array}{l}\text { Shared understand as well as new ideas and } \\
\text { meaning }\end{array}$ \\
\hline
\end{tabular}

\section{The Organizational Learning View}

The organizational learning view largely stems from cognitive psychology. It predominantly adopts an individual level ontology and focuses on individual-learning models (Elkjaer, 2003; Leroy \& Ramanantsoa, 1997), which are then extended to the level of organization without being fundamentally modified. This individual-learning focus is warranted because individuals are the key repository of knowledge in organizations (Sarwat \& Abbas, 2020). The organizational learning view regards organizations as active and purposive learners, which modify their existing cognitive maps and images (Argyris \& Schön, 1978) and blend adaptive adjustments with manipulative enactment of the environment (Hedberg, 1981). This is in contrast to the traditional view of organizations as 
passive, adaptive and experiential learners (e.g. Levitt \& March, 1988; Nelson \& Winter, 1982). Thus, the organizational learning view emphasizes learning which fundamentally changes the way organizations behave. Knowledge creation in this view is just one of the outcomes of learning; other outcomes include developing cognitive maps/schema, aligning what organizations say and do, etc. (Argyris, 1977, 1999).

The organizational learning view attributes knowledge creation to deep or broad knowledge. Unlike know-what, or the basic mastery of a discipline through training and certification, and knowhow, or the physical ability to produce some action, deep knowledge is the know-why, or the knowledge of the cause-and-effect relationships (Kim, 1993). Other scholars emphasize broad knowledge, such as 'systems thinking' (Senge, 1990), where constituent parts of a phenomenon are combined to form a coherent whole (Sparrow, 1998). Following that, the organizational learning view attempts to identify learning processes that allow an individual to capture the underlying governing variables (Argyris, 1999; Argyris \& Schön, 1978), such as insights (Fiol \& Lyles, 1985), principles (Swieringa $\&$ Wierdsma, 1992) or structures (Senge, 1990). Nonetheless, implicit in this view is the informationprocessing perspective, that is, how information is efficiently processed by human mind, or how organizations encode and store, and later retrieve and use knowledge (e.g. Cyert \& March, 1992).

It is argued that deep/broad knowledge is developed from higher-level as opposed to lower-level learning (Argyris, 1977; Senge, 1900). Scholars have identified the distinction between lower-level and higher-level learning in many ways, such as habit-forming and discovery (Hedberg, 1981), blocked and experimental (Leroy \& Ramanantsoa, 1997), or operational and conceptual, respectively (Kim, 1993). Lower-level learning occurs within a given organizational structure and set of rules, whereas higher-level learning aims to adjust overall rules and norms rather than specific activities or behaviors (Fiol \& Lyles, 1985, pp. 807-808). This emphasis on higher-level learning is central to the organizational learning view. Senge (1990, p. 14 and p. 69), for instance, attributes knowledge creation to 'generative', or deep, learning rather than 'survival', or adaptive/short-term, learning as it is the former that develops 'systems thinking' to deal with complexity and create new knowledge.

The most widely accepted distinction between learning levels is in the shape of Argyris \& Schön's (1978) single and double-loop learning models. Single-loop learning involves a single feed-back loop, which connects detected outcomes of action to organizational strategies and assumptions within a constant framework of the theory-of-action, whereas double-loop learning occurs when mismatches between expected and actual outcomes are corrected by firstly examining and altering the theoryof-action (one feedback loop) and then the actions (another feedback loop) (Argyris, 1977). Theoryof-action, or the 'master program', is the set of cognitive rules and reasoning that are used to design and implement actions (Argyris, 1991, p. 100). In terms of creative outcomes, single-loop learning results in incremental, but not substantial, changes in the theory-of-action, whereas double-loop learning involves changes which could be substantial or transformative, in that the theory-of-action itself could be replaced or radically reoriented (DiBella et al., 1996).

\section{The Knowledge-creation View}

The knowledge-creation view extends Michael Polanyi's (1966, p. 4) oft quoted dictum, 'we can know more than we can tell' and focuses on the notion of tacit knowledge. Nonaka \& Takeuchi (1995, p. 85) argue that '...organization cannot create knowledge by itself. Since tacit knowledge held by individuals is the basis of organizational knowledge creation... which is the rich, untapped source of new knowledge.' Tacit knowledge is the highly subjective insights, intuitions, hunches (Nonaka, 1991) and accumulated experiences (Leroy \& Ramanantsoa, 1997), and is difficult to be formalized, codified, organized or aggregated at a single location (Lam, 2000). It is contrasted with explicit knowledge, or the formal and structured knowledge (Kim, 1993), which is easy to be transformed and acquired and aggregated at a single location (Leroy \& Ramanantsoa, 1997).

Whereas explicit knowledge can be acquired through repetition, reinforcement, or logical deduction and formal study, because tacit knowledge is difficult to articulate, it cannot be transferred 
per se but only shared (Lam, 2000). This sharing could take the form of observation-imitationpractice, joint problem-solving, experience sharing, inter-organizational networking and communities of practice (Nonaka, 1994, Nonaka, Toyama, \& Hirata, 2008), among others. Following that, the knowledge-creation view emphasizes the importance of social interactions (Lam, 2000), that is, interactions with selves, others, artifacts, contexts, and products and producers of situations (Elkjaer, 2003). Underpinning this view is the perspective that reality is emergent and socially constructed, that is, society is constituted in, that is, context-dependent, and constituted by, and cannot be detached from, the interpretative practices of its members (Gherardi \& Nicolini, 2001). Tacit knowledge is internalized through immersion, reflection, assimilation, experience, trial-and-error, etc. (Nonaka, 1994, Nonaka et al., 2008), and together with knowledge sharing, makes knowledge creation 'a way of behaving' (Nonaka, 1991, p. 97) in which knowledge is routinely shared, debated and reflected upon (Nonaka, 1994).

While there have been numerous scholarly discussions on whether or not tacit and explicit knowledge are separate entities (Cook \& Brown, 1999; Gourlay, 2003, 2006; Gourlay \& Nurse, 2005; Janik, 1988; Tsoukas, 2005), the knowledge-creation view regards tacit and explicit knowledge as interchangeable entities. It then attributes knowledge creation to the dynamic interactions between tacit and explicit knowledge (Nonaka, 1991). Specifically, Nonaka (1994) presents four knowledge conversion modes: a) tacit-to-tacit, where the existing tacit knowledge of an individual is converted into new tacit knowledge of another, through the process of `socialization'; b) tacit-to-explicit, where the tacit knowledge of the individual is transformed into explicit knowledge, i.e. communicated to others, through the process of 'externalization'; c) explicit-to-explicit, where explicit information is re-shaped into new explicit knowledge, such as a manual or a workbook, through the process of 'combination'; and d) explicit-to-tacit, where explicit knowledge is transformed into tacit knowledge of others through the process of 'internalization'. These modes repeat and reinforce as a cyclical spiral of interactions.

Central to the knowledge-creation view is the importance of dialogue. Dialogue refers to the dialectical, dynamic and often volatile exchanges between organizational members based on their divergent perspectives, views and opinions. Scholars have earlier recognized the importance of dialogue in varied ways. For example, Phan \& Perdic (2000) in the context of strategic alliances argue that conflict must exist for knowledge creation to occur. Eisenhardt, Kahwajy, \& Bourgeois (1997) note that management teams that challenge one another's thinking develop a more complete understanding of choices and create a richer range of alternatives. Other scholars highlight that conflict must exist to spur team creativity because it results in a wide range of ideas, vetting ideas more closely and ultimately converging on more unconventional solutions (Fairchild \& Hunter, 2014; Skilton \& Dooley, 2010). For the knowledge-creation view, dialogue provides the mechanism to synthesize the conflict, or tension, between creativity and efficiency, differentiation (division) and integration (combining), exploration (discovery) and exploitation (implementation) (Nonaka et al., 2008), among others. Nonaka (1991, p. 104) states, '...dialogue can - indeed, should - involve considerable conflict and disagreement. It is precisely such conflict that pushes employees to question existing premises and make sense of their experience in a new way.' Indeed, the dynamic interactions between tacit and explicit knowledge themselves reflect a dialogue process. The outcome of dialogue is that organizational members are able to sense what others are struggling to articulate as well as articulate their own perspectives (Nonaka, 1994). Dialogue, therefore, not only develops shared, or collective, understanding (Nonaka \& Takeuchi, 1995), but also helps in generating new ideas and meaning, which makes the dialogue meaningful (see Nonaka et al., 2008).

Having outlined the underlying perspectives, focus, prescribed processes and creative outcomes of the two influential views on organizational knowledge creation, the paper now presents the underlying commonalities and key differences of the two views. 


\section{Underlying Commonalities and Key Differences}

The two views are similar and different in a number of ways. This is detailed below, including their relevant critique.

\section{Underlying Commonalities}

The two views have a number of underlying commonalities. The first stems from the way reality is understood. As highlighted earlier, the organizational learning view regards that people construct, or build, cognitive maps, images, models and schema to make sense of the world (McAdam \& McCreedy, 2000) and organize multiple meanings into a manageable set (Daft \& Weick, 1984). Similarly, the knowledge-creation view also takes a constructionist view where reality is essentially constructed from close interaction with self, environment or others (Nonaka \& Takeuchi, 1995; Lam, 2000). Barring their ontological (individual versus collective) differences, both the views consider reality as not something that is given, but something that is constructed or built.

The second commonality relates to the active view of organizations. The organizational learning view's active orientation is a reaction to the traditional view of organizations as passive, adaptive and experiential learners (Levitt \& March, 1988; Nelson \& Winter, 1982). The organizational learning view forms a part of studies that attempt to reverse that traditional view by regarding organizations as active and purposive learners (Argyris \& Schön, 1978). On similar lines, the knowledge-creation view takes an active view of organizations, and regards organizations as knowledge creating entities (Nonaka \& Toyama, 2003), creating new knowledge and information on a continuous basis (Nonaka $\&$ Takeuchi, 1995).

The third underlying commonality relates to the potential link between tacit and deep knowledge. As highlighted earlier, the organizational learning view traces knowledge creation in deep knowledge, whereas the knowledge-creation view traces it in tacit knowledge. However, several scholars have indicated that there could be a link between deep and tacit knowledge. For example, Polanyi (1966) refers to tacit knowledge as subsidiary awareness which is deeper than focal awareness. Similarly, Gourlay (2006) differentiates between inherent and contingent tacit knowledge where the latter is easy to be made explicit but the former is not. This link between tacit and deep knowledge has not been articulated because tacit knowledge thus far has mainly been defined in terms of its conversion character, that is, how easy or difficult it is to express this knowledge, and not in terms of its specific cognitive character. It seems like an all-encompassing notion, such as to include insights, hunches, intuition, know-how, know-why, experiences, metal models, personal schemas, broad knowledge, embedded knowledge, vision, values and ideals (Ancori, Bureth, \& Cohendet, 2000; Lam, 2000), just to name a few. A consequence of this all-encompassing approach is that there exists a tendency to deposit anything and everything that has not been theoretically articulated in the black box of tacit knowledge (see Cowen, David, \& Foray, 2000). Approaching tacit knowledge in terms its cognitive character could allow the link between tacit and deep knowledge to be articulated.

The fourth underlying commonality relates to the role of deviance in learning or knowledge creation. Deviance refers to the anti-dote of a given phenomenon, which is achieved with a departure, conscious or otherwise, from established norms, routines, practices, knowledge bases, etc. The role of deviance in learning is widely recognized (Inkpen \& Crossan, 1995; Shrivastava, 1983), which the two views also unanimously highlight. For example, the organizational learning view regards organizational learning as the detection and correction of mismatch between expected and actual outcomes (Argyris, 1999), and recognizes the importance of failures, crisis and revolution in inducing learning (Argyris, 1977). Similarly, the knowledge-creation view emphasizes the importance of dialectics, or the synthesis of the thesis-antithesis conflict (Nonaka \& Toyama, 2003), or intentional efforts to evoke a sense of crisis (Nonaka et al., 2008).

The final underlying commonality relates to the level of creative outcomes. The organizational learning view regards that whereas the creative outcomes from lower-level learning are incremental, those from higher-level or double-loop learning are substaintial or transformative (DiBella et al., 
1996), i.e. where the thoery-of-action itself could be improved, modified, or even replaced or radically reoriented (Hedberg, 1981). These higher-level creative outcomes are equally shared by the knowledge-creation view, where for instance, in the context of metaphorization, Nonaka, Toyama, \& Byosière (2001, p. 495) highlight, '...the association of two unlike concepts through metaphor often leads to the discovery of new meaning and even to the formation of a new paradigm [italics added for emphasis].' Thus, both the views equate knowledge creation with higher-level creative outcomes.

The abovementioned commonalities suggest that there exists an opportunity to integrate the two views. This integration is important and valuable because it would bring greater coherence and depth in our understanding of organizational knowledge creation, a subject which is increasingly becoming crucial for the future growth of firms. However, the integration of the two views critically depends upon how well the analysis addresses their divergent positions, for which a closer look at their key differences is imperative.

\section{Key Differences}

There are a number of key differences in the two views. The first difference relates to their underlying philosophies and approaches. As highlighted earlier, the organizational learning view mainly adopts an individual ontology, because individuals are regarded as agents through whom organizations learn (Kim, 1993; Shrivastava, 1983). In contrast, the knowledge-creation view gives a cursory focus to the individual level ontology (Easterby-Smith, Crossan, \& Nicolini, 2000) and puts greater emphasis on the collective ontology, such as group and organizational levels. In terms of epistemology, the organizational learning view adopts a perspective that focuses more on how information is processed by individuals and organizations, and later retrieved and used. In contrast, the knowledge-creation view takes a perspective that focuses less on information processing but more on how individuals learn via social interactions and practice. Thus, the organizational learning view is tilted more towards the Cartesian emphasis on the rational thought (or mind) rather than sensory experiences (or body), and vice versa in the case of the knowledge-creation view (Nonaka \& Takeuchi, 1995; see also Nonaka et al., 2001). These underlying perspectives in turn shape how the two views approach the creation of new knowledge.

The second difference relates to the notion of new knowledge. While the organizational learning view regards organizations as active and purposive learners (Argyris \& Schön, 1978), this active orientation is restricted to solving existing problems or improving existing knowledge (see Nonaka et al, 2001). In contrast, the active view of organizations that the knowledge-creation view takes transcends that of the organizational learning view. It regards organizations as creating new knowledge rather than just improvements in existing knowledge (Nonaka \& Toyama, 2003); 'When organizations innovate, they do not simply process information, from outside in, in order to solve existing problems and adapt to a changing environment. They actually create new knowledge and information, from the inside out, in order to redefine both problems and solutions...' (Nonaka \& Takeuchi, 1995, p. 56). By arguing that, the knowledge-creation view shifts the organization's active orientation to a higher level, i.e. from improving knowledge to creating knowledge or from mere problem solving to redefining problems.

The third key difference relates to the processes that are emphasized. As highlighted earlier, the organizational learning view traces knowledge creation in deep knowledge, and subsequently attempts to identify the type of learning that best develops deep knowledge. It thus emphasizes higher-level learning, such as double-loop learning, regarding it as something special. It admits that organizations rarely promote higher-level or double-loop learning (Argyris, 1999; Friedman, 2001), which perhaps serves to make such learning a rare event, and thus special. The knowledge-creation view, on the other hand, plays down the importance of double-loop learning by arguing that it is nothing special, but rather routinely built into knowledge creating organizations and that '...organizations question and reconstruct existing perspectives, frameworks, or premises on a daily basis through continuous process of knowledge creation' (Nonaka et al., 2001, p. 492). Instead, the knowledge-creation view 
emphasizes tacit knowledge, and because such knowledge is difficult to articulate and can mainly be shared rather than transferred (Lam, 2000) it emphasizes interactions. Interactions, as highlighted earlier, could reflect in myriad ways, such as observation-imitation-practice, joint problem-solving activities, experience sharing, communities of practice, etc. (Nonaka, 1994, Nonaka et al., 2008), and, unlike double-loop learning, no one type of process can be regarded as special to be preferred over another because each one of these contributes in part to and has its own role to play in the wider objective of transferring/internalizing tacit knowledge.

Moreover, while the two views recognize the importance of deviance, they differ on how it is to be achieved. For the organizational learning view deviance originates from double-loop learning. Rothman \& Friedman (2001, p. 583) state, 'Double-loop learning is a form of conflict resolution in which organizational members inquire into the reasoning behind the positions they take and the meaning of these positions for them.' For the knowledge-creation view, on the other hand, deviance originates from dialogue, conflict (Nonaka, 1994), or intentional efforts to evoke a sense of crisis (Nonaka et al., 2001).

Related also to the processes is the difference in the direction of analysis and the emphasis on internalization or externalization. Internalization refers to a deeper retention of knowledge in an individual's mind, whereas externalization refers to making knowledge explicit for availability to others. The organizational learning view mainly works backwards in its analysis, for example, from information available external to human mind to how it is processed internally by human mind. This backward movement is also reflected in the movement from the superficial phenomena to their underlying governing variables (Argyris, 1999), insights (Fiol \& Lyles, 1985) or principles (Argyris \& Schön, 1978; Swieringa \& Wierdsma, 1992). As a result, it emphasizes internalization more than externalization, and, perhaps as a consequence of that, learning more than the creative outcomes of learning (see Nonaka, 1994). In contrast, the knowledge-creation view mainly works forwards in its analysis. For example, it works from the tacit knowledge held by individuals to making it available to others (Nonaka et al., 2008). It, therefore, emphasizes externalization more than internalization, such as knowledge sharing and knowledge dissemination (Nonaka, 1994; Nonaka \& Takeuchi, 1995). A natural extension of that forward movement is to focus more on creative outcomes of learning rather than learning per se because the latter is only meaningful in so far as it leads to the former (Nonaka $\&$ Takeuchi, 1995). This forward movement is evident in Nonaka's (1991) metaphor-analogy-model framework where intuitive understanding via imagination/symbols use (or metaphor), reconciles contradictions and makes distinctions (or analogy), to create consistent/systematic logic that resolves differences (model). In other words, both the views are unidirectional in their analysis, that is, backward in the case of organizational learning view and forward in the case of the knowledge-creation view. However, whereas the former view inadequately considers how deep knowledge is creatively translated into action, the latter view inadequately accounts for how individuals and organizations learn to translate action into knowledge (see Easterby-Smith et al., 2000).

What markedly stands out in both the views is that owing to their underlying epistemologies they over-emphasize one or the other element that narrowly fits their own purposes. For instance, the organizational learning view over-emphasizes learning per se (Nonaka, 1994) and because it excessively focuses on individual learning it inadequately accounts for knowledge creation's interactive dynamics (Nonaka \& Takeuchi, 1995). For example, it largely ignores that challenging and questioning of the theory-of-action are not the only ways through which deep/broad knowledge can be developed, and that divergent views and perspectives of different employees, especially at different organizational levels, may equally serve the purpose. Similarly, the knowledge-creation view over-emphasizes knowledge creation's person-embodied aspects (Easterby-Smith et al., 2000; Essers \& Schreinemakers, 1997) and is poorly integrated with individual learning (see Easterby-Smith et al., 2000; Gourlay, 2006; Gourlay \& Nurse, 2005). It ignores that the meaning of words and action can also be modified through processes other than social interactions. 
Having outlined the key differences between the two views, this paper now turns to the integration of the two views.

\section{Integrating Divergent Views on Organizational Knowledge Creation}

The discussion in the previous section suggests that perhaps there is value in integrating the two views. Such integration, following the discussion above, would require an analysis that is able to reconcile the key differences between the two views in terms of: a) information processing and knowledge creation; b) tacit and deep knowledge; c) differences in levels of creative outcomes; and d) the role of deviance.

The paper here brings in the work on knowledge levels advanced earlier in the literature (Akbar, 2003; see also Akbar et al., 2008). This work broadly defines knowledge levels as the ability to view things in a broader perspective based on the degree of coherence in an individual's knowledge. Knowledge is at a lower-level if it is cursory and disjointed. It has traditionally been referred to as know-what and know-how, where the former involves book learning but which is segmented and the latter involves experiential learning but where each learned unit exists independently of another. Knowledge is at a higher level when the degree of independence between different segmented or independent parts of knowledge is reduced. This happens by inter-relating them with a common denominator (see Akbar, 2003 for details). While this seems similar to the systems thinking concept, this definition is able to specify the level at which thinking exists which systems thinking cannot. For example, knowledge could be at different levels $(\alpha, \beta, \gamma$, etc.) depending upon the level at which interlinkages are made. To illustrate that, this paper elaborates upon the example of 'branding', 'product differentiation', 'non-price competition', etc. that Akbar et al (2008) use. An MBA graduate may know all these concepts independently of one another (know-what). S/he may then experience how branding is done in actual practice (know-how). But if his/her knowledge remains at this trajectory s/he is most likely to be only able to 'do', or practice, branding for products that are similar because that is what her/his understanding permits. It is only when the individual understands that the concept of branding also underpins products that are apparently different in nature that her/his understanding shifts to the $\alpha$-level. Similarly, if the individual also understands that branding is underpinned by the concept of product differentiation that her/his knowledge shifts to the $\beta$-level, or that product differentiation itself is governed by the non-price competition concept that her/his knowledge shifts to the $\gamma$-level. In other words, the individual is able to inter-relate as well as rank phenomena at different levels which otherwise existed as segmented pieces of information in her/his mind. The greater the number of different levels that the individual's knowledge is able to capture and rank the deeper is the understanding. Akbar (2003, p. 2004) refers to it as the 'vertical stretch' in understanding.

Having elaborated upon knowledge levels, the subsequent discussion integrates the two views. The integration is divided in to two sub-sections. The first sub-section integrates the information processing perspective with the knowledge creation perspective by using the distinction between a shift and movement in knowledge which, and highlights differences in levels of creative outcomes. The second sub-section integrates the deep knowledge and tacit knowledge based on the problems and the transfer/acquisition of knowledge levels to integrate why deviance in learning and knowledge creation is required.

\section{Shift and Movement in Knowledge}

The shift of knowledge trajectory represents internalization, and, just as the organizational learning view regards, involves the mind processing information and/or experiences to translate action into knowledge. Such processing is inductive because the understanding moves backwards from the explained to the explanatory to capture the cause-and-effect relationship. The differences in levels of experiences that are needed for such inductive learning are determined by the knowledge trajectory that the individual is at. For example, an individual at a lower knowledge trajectory lacks depth in understanding, and hence requires blatantly obvious experiences to be able to understand a given phenomenon. As a result, learning at a lower knowledge trajectory is more likely to be based on 
'hard' sensory experiences, such as from lived-experiences. However, as knowledge progresses to a higher trajectory, the individual develops more depth in understanding and can capture subtle or delicate distinctions, thereby reducing his/her reliance on blatantly obvious experiences to understand phenomena. As a result, learning at a higher trajectory is more likely to be based on 'soft', or less obvious, sensory experiences, for example, simple observation rather than lived experience. This need for less obvious experiences reduces even further as knowledge shift to a yet another (higher) trajectory and the learning from sensory experiences becomes so subtle that it becomes difficult to differentiate it from human thinking. Senge (1990) refers to it as 'highly-trained intuition', or the insight of a seasoned research director who knows instinctively which project to fund and exactly when to do so.

The movement on a given knowledge trajectory represents the creative dimension and translates knowledge or learning into action, thereby bridging the gap between internalization and externalization. This movement is deductive, where the understanding moves forward to creatively apply previously internalized knowledge. For instance, using the previous example, the concept of branding is applied to Product A, Product B, and so on. The greater the number of explained variables (or products in this example) relative to the explanatory (branding concept), the greater is the scale of creative applications. This movement is similar to the concept of analogy that Nonaka uses, that is, where apparently different phenomena, but with similar underlying basis, are interrelated. The scope of creative applications, however, requires a vertical stretch in creative applications, that is where the concept becomes deeper and its creative applications broader. Using our previous example, whereas at the $\alpha$-level it is the concept of branding that is applied to individual products A, B and C, at the $\beta$-level it is the application of product differentiation (a concept deeper than branding) to a group of differentiating activities, such as not just branding, but also merchandizing, sales promotion, etc. The greater the number of levels of explained variables relative to the explanatory, the greater is the scope of creative applications. The analysis can be stretched to the application of non-price competition at the industrial organization level, which could lead to what the organizational learning view regards as the enactment of change (Argyris \& Schön, 1978). It is the level at which creative applications are made that determines what Nonaka et al (2001, p. 495) in the context of metaphorization (or the association of two unlike concepts through metaphor) as, '...the formation of a new paradigm [italics added for emphasis].'

Having integrated the information processing and creative dimensions, and the differences in levels of creative outcomes, the paper now turns to the integration of tacit and deep knowledge as well as their transfer/acquisition, or transformation.

\section{Transformation of Knowledge Levels}

The first integration here is that of tacit and deep knowledge, and their conversion. Akbar (2003) notes that knowledge levels are characterized by inversely-related levels of tacitness and explicitness. It is argued that the acquisition of lower-level knowledge does not involve too many experiential and/or thought-related challenges other than labor-intensive effort. For example, know-what requires simple retention, such as through rote learning, and know-how requires simply living the experience through time. As a result, lower-level knowledge is less connected to deep-seated human experience or thought for it to deeply reside an individual's mind (see Senge, 1990). It is thus characterized by a lower degree of tacitness. In contrast, the acquisition of higher-level knowledge requires internalization, as opposed to simple retention, which requires deeper experiences, such as problems and struggles, as well as considerable thought-related challenges, for sense making. As a result, higher-level knowledge is connected to human experience and thought that deeply reside in an individual's mind, and thus characterized by a higher degree of tacitness. This degree of tacitness is implicit in Polanyi's (1966) subsidiary awareness, or Janik's (1998, pp. 54-56) reference to tacit aspects of human experience which are wholly knowable self-reflectively and by their very nature incapable of precise articulation. 
Scholars have argued that some types of knowledge are difficult to be made explicit than others (Gourlay, 2003; Gourlay \& Nurse, 2005; Janik, 1988; Tsoukas, 2005). For example, as highlighted earlier, Gourlay (2006) argues that inherent tacit knowledge is difficult to be made explicit than contingent tacit knowledge. Akbar (2003) extends that even further by showing differences in levels of explicitness. It is argued that when lower-level knowledge is made explicit, that is, converted from a subjective to an objective regime, it enjoys a higher degree of explicitness because there are not too many deeper experiential/thought-related challenges to be lost in the tacit-explicit conversion. It can be unequivocally and unambiguously communicated, and thus easy to be made explicit (Lam, 2000; Leroy \& Ramanantsoa, 1997). In contrast, higher-level knowledge involves considerable challenges and struggles to be acquired, and when it is made explicit what flows to the recipient are just symbols and words and not the experiential challenges and struggles that underlie that knowledge. These challenges/struggles are person-embodied which get lost in the conversion process and thus are not transferred, making higher-level knowledge characterized by a lower degree of explicitness, devoid of its underlying essence or meaning. That is perhaps why Kleiner \& Roth (1997) have earlier noted that 'best-practice' write-ups are unable to transmit hidden logics and struggles.

The abovementioned insights can now be related to Nonaka's knowledge creation modes. Nonaka inadequately considers explicit knowledge being characterized with different levels of explicitness, such as not just (more explicit) hard, codified knowledge, but also (less explicit) knowledge which is communicated verbally, such as views and opinions, or indeed, (least explicit) knowledge that can only be demonstrated or communicated non-verbally, such as through cues and gestures. Accounting for these shows that Nonaka's tacit-to-tacit and explicit-to-explicit modes are superfluous because for the tacit knowledge of one individual to be converted into that of another it needs to be made explicit in one form or another, and likewise for the existing explicit knowledge to be effectively reshaped it needs to be understood first, i.e. converted into tacit knowledge. That means that perhaps there are only two real knowledge creation patterns, i.e. explicit-to-tacit (internalization) and tacit-to-explicit (externalization), where the former is akin to the information processing or the learning dimension that the organizational learning view emphasizes, whereas the latter is akin to the creative dimension, leading to creative outcomes that the knowledge-creation view emphasizes.

The inverse relationship between the levels of tacitness and explicitness makes it easy to understand why deviance is important in learning and knowledge creation. Earlier, the literature on Critical Realism has recognized that understanding of causal mechanisms originates from contradictory information (Bhaskar, 1986). Because the underlying essence or meaning of higher-level knowledge is lost when it is made explicit, it can only be recaptured with the provision of comparative reference points. Deviance helps in enabling just that. Deviance, in any form or level, provides the 'space' between a given phenomenon and its antidote for it to be subjectively bridged. It provides the opportunity for the individual to be able to compare and contrast the similarities and differences, and hence capture the underlying essence or meaning. The higher the level of knowledge to be internalized, the greater is its complexity, and hence the greater is the level of deviance that is needed to understand it.

Following the above, the organizational learning view and the knowledge-creation view differ only in terms of how deviance is achieved. As argued earlier, an individual at a lower knowledge level is more likely to learn based on 'hard' sensory experiences, and whereas that at a higher-level knowledge is more likely to learn based on 'soft' sensory experiences. Following that, it perhaps seems that an individual whose knowledge is a lower level is more likely to learn from 'hard' forms of deviances, such as failures (Garvin, 1993) or turbulence (Inkpen \& Crossan, 1995). Both the organizational learning view and the knowledge-creation view are congruent in this regard, for example, referring to revolution (Argyris, 1977) and natural crisis (Nonaka et al., 2001), respectively. Where the two views apparently differ, however, relates to the 'soft' forms of deviance which, as highlighted earlier, is all that is needed for learning by an individual with higher-level knowledge. For the organizational learning view this soft form of deviance is obtained from the theory-of-action's challenging and questioning, whereas for the knowledge-creation view it comes from the conflicting 
views/perspectives in an interactive dialogue. These differences stem from their divergent ontological positions - individual or collective. Barring that, both the views, explicitly or implicitly, are referring to the case of higher-level knowledge for knowledge creation.

\section{DISCUSSION AND CONCLUSION}

This paper was aimed at integrating the epistemological positions of the two most influential views on organizational knowledge creation - the organizational learning view and the knowledge-creation view. These views hitherto remain divergent on how new knowledge is created in organizations, the former emphasizing individual learning, deep knowledge and higher-level learning, whereas the latter stressing social construction, tacit knowledge and interactive dialogue. However, there are a number of commonalities which indicate that these two can be integrated and that there is value in doing that. This paper uses Akbar's (2003) theorization of knowledge levels advanced earlier in the literature. Firstly, using the distinction between shifts and movements in knowledge the paper integrates the information processing and creative dimensions as well as identifies how the creative outcomes of the two views are congruent. Secondly, using the degrees of tacitness of knowledge levels the paper integrates tacit knowledge and deep knowledge, and the inverse relationship between the degrees of tacitness and explicitness of knowledge levels to integrate why deviance is important in acquiring knowledge levels, where both the views are congruent in essence, but apparently divergent due to their underlying ontological positions.

By integrating the two influential views on organizational knowledge creation, the paper contributes to bringing about greater coherence in our domain-specific understanding, without compromising the freedom for multiple views and perspectives. Specifically, the paper shows that while the two views appear divergent in a number of areas, in essence they are not. Their differences merely represent surface manifestations of higher-level knowledge, and the recognition of this knowledge is less implicit in the organizational learning view, but more implicit in the knowledge creation view. By focusing on their underlying commonality, that is, higher-level knowledge, this paper reduces the degree of independence between apparently two different domain-specific perspectives and this integration is important because organizational knowledge creation nowadays is crucial for organizational competitiveness and it is imperative that we understand it as a coherent whole rather than having to fish through different perspectives to make sense of it only in parts. Moreover, the paper's integrative attempt not only gives greater academic respect to the organizational knowledge creation discipline, but also opens up more freedom for a variety of interpretations and new meaning/ insights. The subsequent discussion highlights four potential interpretations and meaning/insights.

Potential Meaning 1: The first area of potential meaning relates to the processes that the two views (over)emphasize. The organizational learning view emphasizes information processing and internalization, whereas the knowledge-creation view emphasizes externalization and creative outcomes. This paper shows how these apparently divergent views actually complement each other along the knowledge creation continuum. Information processing and internalization represent the explicit-to-tacit dimension, whereas the externalization represents the tacit-to-explicit dimension, and knowledge creation involves movement from one dimension to another. By doing that, the paper not only gives a more balanced picture of knowledge creation not captured before, but also supports and extends earlier exhortations that tacit and explicit knowledge are two ends of a continuum (Gourlay, 2006; Tsoukas, 2005).

Potential Meaning 2: The second potential interpretation relates to the issue of whether there is something called 'tacit knowledge' or only 'knowledge which is tacit' (e.g. Akbar, 2003; Gourlay, 2003). The word 'tacit' appearing as a prefix in the 'tacit knowledge' label suggests that the latter is something 'remarkably different' from and falls beyond the ambit of' the traditional discussions on knowledge. This paper by linking tacit knowledge with deep knowledge suggests that tacit knowledge is not something inexplicable, but rather just one of the many characters of knowledge levels; others 
include explicitness, depth, application potential, articulation, etc. In other words, while the label 'tacit knowledge' could be a useful reference term, it merely represents a mystified branding of higher-level knowledge that has been amply discussed in the literature earlier. This insight obviates the need to go beyond the ambit of the traditional discussions on knowledge.

Potential Meaning 3: The final potential meaning relates to whether knowledge creation is about solving existing problems and improving existing knowledge as the organizational learning view appears to suggest, or is it about redefining problems/solutions and creating entirely new knowledge as the knowledge-creation view argues. Based on the analysis presented in this paper, it could be argued that an individual or organization with lower-level knowledge lacks relative depth in understanding, and hence is more likely to settle with solving existing problems and improving existing knowledge, whereas that at a higher-level knowledge has greater depth in understanding, and hence is more likely to redefine problems and create new knowledge. However, this paper suggests that if the analysis is stretched in levels the debate becomes rather superfluous because along shifts to higher knowledge trajectories the difference between solving and redefining problems successively reduces. For example, along progression to higher levels the scope of the knowledge increases to such high levels that even if an action is aiming to solve an existing problem the outcome will turn out to be the redefinition of the problem, irrespective of how the outcome is labeled or referred to.

\section{Managerial Implications}

The analysis presented in this paper is also useful for managers. While the notion of tacit knowledge has become popular over the years, it remains vague (Cowen et al., 2000; Tsoukas, 2005) and its cognitive character has not been concretely articulated. It appears to be all encompassing, to include almost everything related to mind, such as insights, hunches, intuition, know-how, know-why, experiences, metal models, personal schemas, vision, values and ideals (Ancori et al., 2000; Lam, 2000; Nonaka $\&$ Takeuchi, 1995). This theoretical vagueness does not give enough guidance to managers as to what specific type of knowledge should they develop to enact knowledge creation, other than relying on an individual's 'mysterious' tacit knowledge. The analysis of knowledge levels that this paper presents helps managers in demystifying tacit knowledge and, instead, highlighting the importance of higher-level knowledge for managers wishing to enact knowledge creation.

The paper's analysis also allows managers an integrated focus for knowledge creation. While learning and knowledge creation are known to be inter-connected (Argyris \& Schön, 1978; Nonaka $\&$ Takeuchi, 1995), it is difficult for managers to concretely spell out their inter-connection. The analysis presented in this paper helps managers to do just that. It shifts managerial understanding from the apparent constructs to their underlying common basis. This shift allows managers to view learning and knowledge creation as two coherent concepts, thereby enabling mangers to concertedly devote their efforts to enact the two concepts as part of a coherent whole. Moreover, scholars have exhorted that learning or knowledge-creating behaviors are merely a reflection of the underlying thinking and knowledge (Akbar, 2003; Brix, 2017; Phan and Perdic, 2000). The analysis that this paper presents attempts to concretely establish that link. This in turn allows managerial efforts to fundamentally change the underlying thinking/knowledge and result in changes which are enduring rather than momentary. Managers as a result will be able to channel scarce resources towards a lasting organizational change, thereby enacting as well as sustaining knowledge creation.

\section{LIMITATIONS AND RESEARCH DIRECTIONS}

This paper is not without limitations. One obvious limitation is that the paper focuses on epistemology rather than ontology. Future researchers can thus examine whether or not the divergent ontological positions of the two views can also be integrated along knowledge levels. On similar lines, researchers can undertake a more detailed integration of the fundamental debates in learning and knowledge creation, such as passive versus active learning (for example, Argyris \& Schön, 1978; Hedberg, 1981; 
Levitt \& March, 1988; Nelson \& Winter, 1982), or the replication versus creation debate (for example, Cyert \& March, 1992; Vezzoli et al., 2017). A yet another potential area of integration is to extend the essence of this paper to empirically examine how differences in levels of sensory experiences relate to those in knowledge levels which could throw greater light on the Western and Japanese (Eastern) approaches to knowledge creation. But to do that a critical and challenging step is to develop specific measures of knowledge levels, which no study has thus far attempted. Developing these measures would also help in investigating the relationship between knowledge levels and differences in levels of creative outcomes. 


\section{REFERENCES}

Akbar, H. (2003). Knowledge levels and their transformation: Towards the integration of knowledge creation and individual learning. Journal of Management Studies, 40(8), 1997-2021. doi:10.1046/j.1467-6486.2003.00409.x

Akbar, H., Baruch, Y., \& Tzokas, N. (2008). The translation of higher-level knowledge into managerial and creative competencies. International Journal of Learning and Intellectual Capital, 5(2), 223-240. doi:10.1504/ IJLIC.2008.020153

Alavi, M., \& Leidner, D. (2001). Knowledge management and knowledge management systems: Conceptual foundations and research issues. Management Information Systems Quarterly, 25(1), $107-136$. doi: $10.2307 / 3250961$

Alvesson, M., \& Karreman, D. (2001). Odd couples: Making sense of the curious concept of knowledge management. Journal of Management Studies, 38(7), 995-1018. doi:10.1111/1467-6486.00269

Ancori, B., Bureth, A., \& Cohendet, P. (2000). The economics of knowledge: The debate about codification and tacit knowledge. Industrial and Corporate Change, 9(2), 255-287. doi:10.1093/icc/9.2.255

Argyris, C. (1977). Double loop learning in organizations. Harvard Business Review, 55(5), 115-125.

Argyris, C. (1991). Teaching smart people how to learn. Harvard Business Review, 69(3), 99-109.

Argyris, C. (1999). On organizational learning. Blackwell Publishers.

Argyris, C., \& Schön, D. (1978). Organizational learning. Addison-Wesley.

Argyris, C., \& Schön, D. (1999). On organizational learning. Wiley-Blackwell.

Bhaskar, R. (1986). Scientific realism and human emancipation. Verso.

Brix, J. (2017). Exploring knowledge creation processes as a source of organizational learning: A longitudinal case study of a public innovation project. Scandinavian Journal of Management, 33(2), 113-127. doi:10.1016/j. scaman.2017.05.001

Campanella, F., Derhy, A., \& Gangi, F. (2019). Knowledge management and value creation in the post-crisis banking system. Journal of Knowledge Management, 23(2), 263-278. doi:10.1108/JKM-11-2017-0506

Cook, S. D. N., \& Brown, J. S. (1999). Bridging epistemologies: The generative dance between organizational knowledge and organizational knowing. Organization Science, 10(4), 381-400. doi:10.1287/orsc.10.4.381

Cowen, R., David, P. A., \& Foray, D. (2000). The explicit economics of knowledge codification and tacitness. Industrial and Corporate Change, 9(2), 211-253. doi:10.1093/icc/9.2.211

Cyert, R. M., \& March, J. G. (1992). A behavioural theory of the firm (2nd ed.). Blackwell.

Daft, R. L., \& Weick, K. E. (1984). 'Toward a model of organizations as interpretation systems. Academy of Management Review, 9(2), 284-295. doi:10.5465/amr.1984.4277657

DiBella, A. J., Nevis, E. C., \& Gould, J. M. (1996). Understanding organizational learning capability. Journal of Management Studies, 33(3), 361-379. doi:10.1111/j.1467-6486.1996.tb00806.x

Easterby-Smith, M., Antonacopoulou, E., Simm, D., \& Lyles, M. (2004). Constructing contributions to organizational learning: Argyris and the next generation. Management Learning, 35(4), 371-380. doi:10.1177/1350507604048268

Easterby-Smith, M., Crossan, M., \& Nicolini, D. (2000). 'Organizational learning: Debates past, present and future. Journal of Management Studies, 37(6), 783-796. doi:10.1111/1467-6486.00203

Eisenhardt, K. M., Kahwajy, J. L., \& Bourgeois, L. J. III. (1997). Conflict and strategic choice: How top management teams disagree. California Management Review, 39(2), 42-62. doi:10.2307/41165886

Elkjaer, B. (2003). Social learning theory: learning as participation in social processes. In M. Easterby-Smith \& M. A. Lyles (Eds.), The Blackwell handbook of organizational learning and knowledge management (pp. 38-53). Blackwell. 
Essers, J., \& Schreinemakers, J. (1997). Nonaka's subjectivist conception of knowledge in corporate knowledge management. Knowledge Organization, 24(1), 24-32.

Fairchild, J., \& Hunter, S. T. (2014). "We've got creative differences". The effects of task conflict and participative safety on team creative performance. The Journal of Creative Behavior, 48(1), 64-87. doi:10.1002/jocb.41

Fiol, C. M., \& Lyles, M. A. (1985). 'Organizational learning. Academy of Management Review, 10(4), 803-813. doi:10.5465/amr.1985.4279103

Friedman, V. J. (2001). The individual as agent of organizational learning. In M. Dierkes, A. B. Antal, J. Child, \& I. Nonaka (Eds.), Handbook of organizational learning and knowledge (pp. 398-414). Oxford University Press.

Gärtner, C. (2013). Cognition, knowing and learning in the flesh: Six views on embodied knowing in organization studies. Scandinavian Journal of Management, 29(4), 338-354. doi:10.1016/j.scaman.2013.07.005

Garvin, D. A. (1993). Building a learning organization. Harvard Business Review, 71(4), 78-91. PMID:10127041

Gherardi, S., \& Nicolini, D. (2001). The sociological foundations of organizational learning. In M. Dierkes, A. B. Antal, J. Child, J., \& I. Nonaka. (Eds.), Handbook of organizational learning and knowledge (pp. 35-60). New York: Oxford University Press.

Gourlay, S. (2003). The SECI model of knowledge creation: Some empirical shortcomings. Proceedings of the Fourth European Conference on Knowledge Management, 377-386.

Gourlay, S. (2006). Conceptualizing knowledge creation: A critique of Nonaka's theory. Journal of Management Studies, 43(7), 1415-1641. doi:10.1111/j.1467-6486.2006.00637.x

Gourlay, S., \& Nurse, A. (2005). Flaws in the "Engine" of knowledge creation. In A. F. Buono \& F. Poulfelt (Eds.), Challenges and issues in knowledge management (pp. 293-315). IAP Press.

Hedberg, B. (1981). How organizations learn and unlearn. In P. C. Nystrom \& W. Starbuck (Eds.), Handbook of organizational design (Vol. 1, pp. 3-27). Oxford University Press.

Inkpen, A. C., \& Crossan, M. M. (1995). Believing is seeing: Joint ventures and organizational learning. Journal of Management Studies, 32(5), 595-618. doi:10.1111/j.1467-6486.1995.tb00790.x

Janik, A. (1988). Tacit knowledge, working life, and scientific method. In B. Göranzon \& I. Josefson (Eds.), Knowledge, skill and artificial intelligence (pp. 53-63). Springer-Verlag. doi:10.1007/978-1-4471-1632-5_6

Kane, G. C. (2017). The evolutionary implications of social media for organizational knowledge management. Information and Organization, 27(1), 37-46. doi:10.1016/j.infoandorg.2017.01.001

Kim, D. H. (1993). The link between individual and organizational learning. Sloan Management Review, 35(1), 37-50.

Kleiner, A., \& Roth, G. (1997). How to make experience your company's best teacher. Harvard Business Review, 75(5), 172-177. PMID:10170330

Lam, A. (2000). Tacit knowledge, organizational learning and societal institutions: An integrated framework. Organization Studies, 21(3), 487-513. doi:10.1177/0170840600213001

Leroy, F., \& Ramanantsoa, B. (1997). The cognitive and behavioral dimensions of organizational learning in a merger: An empirical study. Journal of Management Studies, 34(6), 871-894. doi:10.1111/1467-6486.00076

Levitt, B., \& March, J. G. (1988). Organizational learning. Annual Review of Sociology, 14(1), 319-340. doi:10.1146/annurev.so.14.080188.001535

McAdam, R., \& McCreedy, S. (1999). A critical review of knowledge management models. The Learning Organization, 6(3), 91-100. doi:10.1108/09696479910270416

Mehralian, G., Nazari, J. A., \& Ghasemzadeh, P. (2018). The effects of knowledge creation process on organizational performance using the BSC approach: The mediating role of intellectual capital. Journal of Knowledge Management, 22(4), 802-823. doi:10.1108/JKM-10-2016-0457

Nelson, R. R., \& Winter, S. G. (1982). An evolutionary theory of economic change. Harvard University Press. 
Nonaka, I. (1991). The knowledge-creating company. Harvard Business Review, 69(6), 96-104.

Nonaka, I. (1994). A dynamic theory of organizational knowledge creation. Organization Science, 5(1), 14-37. doi:10.1287/orsc.5.1.14

Nonaka, I., \& Takeuchi, H. (1995). The knowledge creating company: How Japanese companies create the dynamics of innovation. Oxford University Press.

Nonaka, I., \& Toyama, R. (2003). The knowledge-creating theory revisited: Knowledge creation as a synthesizing process. Knowledge Management Research and Practice, 1(1), 2-10. doi:10.1057/palgrave.kmrp.8500001

Nonaka, I., Toyama, R., \& Byosière, P. (2001). A theory of organizational knowledge creation: Understanding the dynamic process of creating knowledge. In M. Dierkes, A. B. Antal, J. Child, \& I. Nonaka (Eds.), Handbook of organizational learning and knowledge (pp. 491-517). Oxford University Press.

Nonaka, I., Toyama, R., \& Hirata, T. (2008). Managing flow: A process theory of the knowledge-based firm. Palgrave Macmillan. doi:10.1057/9780230583702

Nonaka, I., \& von Krogh, G. (2009). Tacit knowledge and knowledge conversion: Controversy and advancement in organizational knowledge creation theory. Organization Science, 20(3), 635-652. doi:10.1287/orsc.1080.0412

Phan, P. H., \& Perdic, T. (2000). Knowledge creation in strategic alliances: Another look at organizational learning. Asia Pacific Journal of Management, 17(2), 201-222. doi:10.1023/A:1015857525048

Polanyi, M. (1966). The logic of tacit inference. Philosophy (London, England), 41(155), 1-18. doi:10.1017/ S0031819100066110

Rothman, J., \& Friedman, V. J. (2001). Identity, conflict, and organizational learning. In M. Dierkes, A. B. Antal, J. Child, \& I. Nonaka (Eds.), Handbook of organizational learning and knowledge (pp. 582-597). Oxford University Press.

Sarwat, N., \& Abbas, M. (2020). Individual knowledge creation ability: Dispositional antecedents and relationship to innovative performance. European Journal of Innovation Management. Advance online publication. doi:10.1108/EJIM-05-2020-0198

Scotland, J. (2012). Exploring the philosophical underpinnings of research: Relating ontology and epistemology to the methodology and methods of the scientific, interpretive, and critical research paradigms. English Language Teaching, 5(9), 9-16. doi:10.5539/elt.v5n9p9

Senge, P. M. (1990). The fifth discipline. Doubleday.

Shrivastava, P. (1983). A typology of organizational learning systems. Journal of Management Studies, 20(1), 1-28. doi:10.1111/j.1467-6486.1983.tb00195.x

Skilton, P. F., \& Dooley, K. J. (2010). The effects of repeat collaboration on creative abrasion. Academy of Management Journal, 35(1), 118-134.

Sparrow, J. (1998). Knowledge in organizations: Access to thinking at work. Sage Publications.

Stoyanov, S. (2018). An analysis of Ikujiro Nonaka's A Dynamic Theory of Organizational Knowledge Creation. CRC Press.

Swieringa, J., \& Wierdsma, A. (1992). Becoming a learning organization. Addison-Wesley.

Tsoukas, H. (2005). Do we really understand tacit knowledge. In H. Tsoukas (Ed.), Complex knowledge: Studies in organizational epistemology (pp. 141-161). Oxford University Press.

Vezzoli, C., Kohtala, C., Srinivasan, A., Xin, L., Fasakul, M., Sateesh, D., \& Diehl, J. C. (2017). Product-service system design for sustainability. Routledge. doi:10.4324/9781351278003

Von Krogh, G., Ichijo, K., \& Nonaka, I. (2000). Enabling knowledge creation: How to unlock the mystery of tacit knowledge and release the power of innovation. Oxford University Press. doi:10.1007/978-1-349-62753-0 